\title{
Longitudinal effects of stunting and wasting on academic performance of primary school boys: The North-West Child-Health-Integrated-Learning and Development study
}

\begin{tabular}{|c|c|}
\hline \multicolumn{2}{|c|}{$\begin{array}{l}\text { Authors: } \\
\text { Dané Coetzee }{ }^{1} \\
\text { Wilmarié du Plessis }{ }^{1} \\
\text { Deidré van Staden }\end{array}$} \\
\hline \multicolumn{2}{|c|}{$\begin{array}{l}\text { Affiliations: } \\
\text { 1Physical Activity, Sport and } \\
\text { Recreation (PhASRec), Focus } \\
\text { Area, Faculty of Health } \\
\text { Sciences, North-West } \\
\text { University, Potchefstroom, } \\
\text { South Africa }\end{array}$} \\
\hline \multicolumn{2}{|c|}{$\begin{array}{l}\text { Corresponding author: } \\
\text { Dané Coetzee, } \\
\text { dane.coetzee@nwu.ac.za }\end{array}$} \\
\hline \multicolumn{2}{|c|}{$\begin{array}{l}\text { Dates: } \\
\text { Received: } 13 \text { Apr. } 2020 \\
\text { Accepted: } 07 \text { Sept. } 2020 \\
\text { Published: } 15 \text { Dec. } 2020\end{array}$} \\
\hline \multicolumn{2}{|c|}{$\begin{array}{l}\text { How to cite this article: } \\
\text { Coetzee, D., Du Plessis, W. \& } \\
\text { Van Staden, D., 2020, } \\
\text { 'Longitudinal effects of } \\
\text { stunting and wasting on } \\
\text { academic performance of } \\
\text { primary school boys: The } \\
\text { North-West Child-Health- } \\
\text { Integrated-Learning and } \\
\text { Development study', South } \\
\text { African Journal of Childhood } \\
\text { Education 10(1), a863. } \\
\text { https://doi.org/10.4102/ } \\
\text { sajce.v10i1.863 }\end{array}$} \\
\hline \multicolumn{2}{|c|}{$\begin{array}{l}\text { Copyright: } \\
\text { (c) 2020. The Authors. } \\
\text { Licensee: AOSIS. This } \\
\text { is licensed under the } \\
\text { Creative Commons } \\
\text { Attribution License. }\end{array}$} \\
\hline \multicolumn{2}{|l|}{ Read online: } \\
\hline 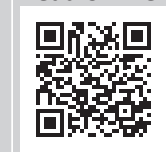 & $\begin{array}{l}\text { Scan this QR } \\
\text { code with your } \\
\text { smart phone or } \\
\text { mobile device } \\
\text { to read online. }\end{array}$ \\
\hline
\end{tabular}

Background: A worldwide occurrence like stunting and wasting affects both children's health and academic performance.

Aim: The aim of the study was to determine the effect of stunting and wasting on academic performance amongst primary school boys over a period of 7 years (2010-2016) in the North West Province of South Africa.

Methods: The study forms part of a longitudinal research design, the North-West Child-Health-Integrated-Learning and Development (NW-CHILD) study, stretched over a period of 7 years from 2010 to 2016. Baseline measurements and two follow-up measurements of boys $(n=181)$ formed part of this study. Two-way frequency tables and analyses of variance (ANOVA) tests were used to analyse the data $(p \leq 0.05)$.

Setting: The study was conducted in the North West Province of South Africa.

Results: The prevalence of stunting $(3.32 \%-6.63 \%)$ and wasting $(3.86 \%-6.63 \%)$ increased each year from 2010 to 2016. Language, mathematics and overall average academic scores were affected statistically by stunting and wasting $(p \leq 0.05)$. Over a period of 7 years (overall), it was found that stunting and wasting influenced academic performance, especially concerning language and mathematic subjects.

Conclusion: Stunted and wasted primary school boys in the North West Province of South Africa reported a strong negative association with academic performance, especially language and mathematic subjects. Limited data are available concerning stunting, wasting and academic performance, and further studies are therefore recommended to strengthen and support the findings of this study with regard to a better understanding of the effect.

Keywords: academic performance; boys; primary school; stunting; wasting.

\section{Introduction}

Wasting and stunting affect several areas of child development, and these include cognitive communication, academic achievement, motor skills and psychological development (Daniels et al. 2005; Van Niekerk et al. 2015; Wingfield et al. 2011). Furthermore, it has been reported that malnutrition leads to several health problems in children and includes weight loss (that could lead to wasting), growth stunting, poor immune systems that lead to poor resistance to infections, dehydration, behavioural problems, poor cognitive development and premature deaths (Brown \& Pollitt 1996; Saunders et al. 2014). Fifty million children under the age of 5 years worldwide are affected by wasting, whilst $16 \mathrm{~m}$ of these children are severely wasted (WHO 2016). Wasting refers to the inadequate mass for height (too thin for height) (Victora 1991; WHO 2016) and can be indicated by a Z-score (less than -2 standard deviations [SDs]) using body mass index (BMI) for age and percentiles below five (De Onis et al. 2006). In recent years it seems as though wasting is decreasing worldwide; however, the prevalence of wasting remains a problem (UNICEF 2016).

Several studies reported that the prevalence of wasting amongst boys between the ages of five and 12 years, from different countries (South Nigeria, Ethiopia, Pakistan, Australia and Egypt), is still a major concern (Ene-Obong et al. 2012; Mushtaq et al. 2011; Pearce et al. 2016; Rashmi et al. 2015; Sharaf \& Rashad 2016). These researchers indicated that the overall prevalence of wasting ranges from $6.0 \%$ to $54.3 \%$, whilst children $(19.0 \%)$ tend to have a higher prevalence of 
wasting compared with adolescents (8.3\%). Furthermore, children younger than 5 years may suffer from moderate to severe wasting. Additionally, various researchers reported that children from rural areas (33.0\%) had a higher prevalence of wasting when compared with children from urban areas (20.0\%) in Pakistan and central India (Mushtaq et al. 2011; Patil et al. 2016). In a trend analysis, it was confirmed that wasting was more prevalent amongst boys (8.6\% in 2009) when compared with girls (5.6\% in 2009) (Matanda, Mittelmark \& Kigaru 2014). These researchers also reported that the boys from rural areas (8.8\%) had higher wasting prevalence when compared with urban areas $(7.4 \%)$. However, these researchers indicated that wasting amongst the different demographic settings (in Kenya) decreased from 1998 to 2009 (9.4\% - 8.8\%). Confirming the latter results, higher wasting prevalence was found amongst boys (2.8\%) in rural areas (13.7\%) when compared with urban areas (11.1\%) in Argentina (Nuñez et al. 2016). Various researchers have reported that the prevalence of wasting in South Africa (North West Province, Northern Cape Province and South Africa based on consensus data) ranges from $1.4 \%$ to $23.4 \%$ (Kruger et al. 2012, 2014; Walsh, Dannhauser \& Joubert 2001) and that wasting is more prevalent amongst African children when compared with Caucasian children. Research regarding the prevalence of wasting was more prevalent in rural areas when compared with urban areas, ranging from moderate to severe wasting (Steenkamp, Lategan \& Raubenheimer 2016; Tomlinson et al. 2016). In Monyeki et al.'s (2008) longitudinal study (1996-2003) on children aged 3-10 years in the Ellisras District of South Africa, it was found that boys' prevalence of wasting ranged as follows: mild (23.6\%), moderate $(14.9 \%)$ and severe $(43.6 \%)$. The boys presented higher wasting percentages and persistence when compared with the first measurement. According to Benefice et al. (2006), children who are wasted may have long-term consequences such as stunting.

Stunting is also a global problem and affects millions of boys worldwide (UNICEF 2016). Stunting refers to a child's Z-scores of height-for-age ratio below -2 SDs from the median according to the World Health Organization (WHO) Child Growth Standards (WHO 2014). Studies (from developed and developing countries) have reported that the prevalence of stunting in children between the ages of five and 19 years ranges from $17.4 \%$ to $27.0 \%$, with $22.2 \%$ of children being severely stunted (with boys being more stunted than girls) (De Onis, Blössner \& Borghi 2011; Senbanjo et al. 2011). De Onis et al. (2011) also reported in 2010, that $167 \mathrm{~m}$ children from developing countries were stunted. These researchers further indicated that the prevalence of stunting amongst the African region has increased over the past decade (in developed and developing countries). Furthermore, the WHO (2015) reported that, globally, almost one in every four children $(156 \mathrm{~m})$ below 5 years of age (thus adding up to $23 \%$ of children) were stunted and that the highest prevalence of stunting was observed in the African region (38\%).
Studies from Africa, more specifically South Africa, reported that the prevalence of stunting also affects boys. In this regard, researchers have reported that boys younger than 5 years of age are more affected by stunting than school children and the prevalence of stunting ranges between $0 \%$ and $43.6 \%$ amongst boys (aged 6-13 years) in the Ellisras District (Motswagole et al. 2012). A study by Shisana (2014) reported the prevalence of stunting amongst the different provinces of South Africa, indicating the following: North West with 23.7\%, Mpumalanga with $23.1 \%$ and Northern Cape Province with $22.8 \%$ of children being stunted. Furthermore, these researchers indicated that boys from rural areas $(23.2 \%)$ are more affected by stunting when compared with boys from urban areas (13.6\%) (Shisana 2014). Results from the Western Cape, Northern Cape and Free State reported that $47 \%$ of children were moderately stunted and 32\% were severely stunted (Steenkamp et al. 2016). With regard to longitudinal studies in South Africa, the Ellisras District Transition and Health during Urbanisation of South Africans (THUSA BANA) study indicated that stunting amongst boys ranged from $8 \%$ to $47.6 \%$ in the North West province (Monyeki et al. 2008). Another study by Kruger et al. (2014) in the North West Province reported that $4.29 \%$ of the children were stunted, with $4.06 \%$ of them being boys. Adding to this, these researchers reported that African Grade 1 learners had a higher stunting prevalence when compared with Caucasian learners (6\% vs. 0\%). The Ellisras Longitudinal Growth and Health Study (ELS) in the Limpopo Province reported an overall prevalence of stunting being $6.1 \%$, whilst $13.7 \%$ of the boys in this study were stunted (Motswagole et al. 2012). Various researchers reported a relationship between cognitive abilities, scholastic achievements, early school failure and stunting (Brown \& Pollitt 1996; Mendez \& Adair 1999; Rashmi et al. 2015; Victoria et al. 2008; Walton \& Allen 2011), internationally and locally.

According to various researchers, a strong link between malnutrition and academic performance exists (Benton 2010; Dewey \& Begum 2011; Hughess \& Bryan 2003). Benton (2010) is of the opinion that malnutrition occurs in the first year of the child's life and could have long-term effects on the cognitive abilities (that could include lower intelligence coefficient and academic performance) and behaviour of the child. Stunting and wasting are associated with cognitive communication and developmental delays, and therefore a strong correlation was found amongst stunted and wasted children and their academic performance. Studies conducted in Sweden, Australia, Finland and the United States of America indicated that wasted children had poor cognitive and academic development, higher dropout or failure rates, higher absenteeism from school, lower mathematic marks and learned at a slower rate when compared with their peers (Alaimo, Olson \& Frongillo 2001; Hughess \& Bryan 2003). Several studies have found a significant association between wasting and lower academic performance amongst children between the ages of three and 14 years in Bangladesh and Sri Lanka (Cook \& Jeng 2009; Golam et al. 2014) as well as poor concentration (Wisniewski 2010). Wasting and stunting 
were reported to be positively associated with lower grades in mathematics and language subjects, as well as cognitive and communication development (Hollar et al. 2010; Pearce et al. 2016; Sudfeld et al. 2015). Moreover, children (Peru and Jamaica) suffering from severe stunting tested up to 10 points lower on the Wechsler Intelligence Scale for Children Revised test, and these children especially struggled with spelling and reading (Berkman et al. 2002; Chang et al. 2010). Prendergast and Humphrey (2014) reported in their review article that various studies confirmed that children affected by stunting do have lower cognitive development, and these children tend not to enrol for school or enrol much later. This may be because of these children looking immature. Furthermore, these researchers indicated that stunted children have lower grades and have a lack of sufficient memory when compared with non-stunted children (Prendergast \& Humphrey 2014). Miller et al. (2015) reported that stunting and severe stunting were negatively associated with learning and affected not only these children's literacy skills, but also their numeracy development (Patil et al. 2016).

Stunting and wasting's effect on children worldwide was observed, and the same tendency can be observed in South Africa. According to Casale, Desmond and Richter (2014), children younger than 5 years and primary school children's schooling and cognitive development are affected by stunting. Longitudinal studies conducted in the rural areas of Ellisras in South Africa reported a positive association between wasting and English and mathematics performance amongst Grade 4-8 learners (Matabane, Liebenberg \& Monyeki 2012; Themane et al. 2003). Moreover, these researchers also reported a negative association between academic intelligence performance and growth parameters amongst boys in Grade 4-8. Furthermore, stunted South African children have lower cognitive development, and these children have lower academic achievements when compared with non-stunted children (Skosana 2016). From the literature, it seems that boys show lower academic achievements when they are stunted or wasted compared with their healthy peers.

It is clear from the above literature that stunting and wasting are not just worldwide occurrences, but also a problem in South Africa, impacting school boys' academic performance. Longitudinal studies regarding stunting, wasting and the effect on academic performance (overall and individual subjects) in South Africa are limited. However, studies have not investigated gender differences concerning stunting, wasting and its effect on academic performance. Thus, it strengthens this study, as boys were taken into consideration. Therefore, the aim of this study was to determine the effect of stunting and wasting on academic performance over a period of 7 years on primary school boys in the North West Province of South Africa.

Studies and research regarding the effect of body composition on academic performance on South African boys are still limited. These findings will be beneficial for the Department of Basic Education, Government, schools, teachers, 'Kinderkinetics' and other healthcare professionals with regard to meaningful statistics about stunting and wasting, intervention and physical activity or nutritional programmes regarding children in South Africa. These findings will also provide a profile regarding boys' physical development, health and scholastic skills. Furthermore, the findings will help to determine whether these issues are related to SES and race when focussing on primary school boys. (In this article SES refers to the socio-economic status of the children, predetermined by their school setting, ranging from Quintile 1 to 5. Quintile 1 schools receiving the most financial support from the government and Quintile 5, receiving the least.)

\section{Research methods and design}

\section{Research design}

This study forms part of a longitudinal research design, the North-West Child-Health-Integrated-Learning and Development (NW-CHILD) study and stretched over a period of 7 years (2010-2016). A baseline measurement and two follow-up measurements were included. The baseline data were collected in 2010, the first follow-up measurement was conducted in 2013 and the second follow-up in 2016, in the North West Province of South Africa. The four regions that formed part of this study was randomly selected (please see description of the participants for more details).

\section{Participants and research setting}

The sample was selected by means of stratified random sampling in conjunction with the Statistical Consultation Service of the University of Potchefstroom, North West Province. To determine the sample for baseline measurements, a list of names of schools in the North West Province was obtained from the Department of Basic Education. From the list of schools of the North West Province, which contains eight education districts and which each represented 12-22 regions with about 20 schools (minimum 12, maximum 47) per region, 4 regions and 20 schools were randomly selected with regard to population density and school status. In South Africa the Department of Basic Education divides schools into five Quintiles (categories) on the basis of their poverty classification (Hall \& Giese 2009), where Quintile 1 represents the least well-off schools, whilst Quintile 5 represents the bestoff schools. The poverty classification of schools is carried out in accordance with the national poverty table as compiled by the Treasury (Hall \& Giese 2009) and includes the income levels, dependency relations as well as the literacy levels of the inhabitants of the area (Hall \& Giese 2009; Stats SA 2013a). For the purposes of this study the five Quintiles were only divided into two groups, where the low SES group represented Quintiles 1-3 and the high SES group Quintiles 4 and 5.

In 2010 (the initial measurement), Grade 1 boys $(n=419)$ participated in the North West Province of South Africa. Boys of all races were randomly selected from the list of population density and school status, where Quintile 1 represented schools from low SES areas and Quintile 5 represented schools from 
high SES areas. For the purpose of this study, Quintiles 1-3 ( $n=$ 92) were combined as low SES and Quintiles $4-5(n=89)$ as high SES. During the first follow-up measurements in 2013, 282 boys were still available. The last follow-up measurements were conducted in 2016, with most of the learners in Grade 7. This group consisted of 181 boys (63 Caucasian, 118 African and Mixed race boys). This group was divided into SES groups. Only data from the boys from all three measurements were utilised for the purposes of this study.

\section{Measuring instruments}

\section{Body composition, stunting and wasting}

The anthropometric measurements include body mass $(\mathrm{kg})$, height $(\mathrm{cm})$, waist circumference $(\mathrm{cm})$ and three skinfolds (sub-scapular, triceps and medial calf) (mm). Trained postgraduate students in Human Movement Sciences, specialising in Kinderkinetics, measured all the anthropometrical variables. Anthropometric measurements were taken by an anthropometrist to ensure quality and inter-tester reliability, in accordance with the protocol of the International Society for the Advancement of Kinanthropometry (Stewart et al. 2011). Height was measured by using a portable stadiometer to the nearest $0.1 \mathrm{~cm}$, and body mass was measured to the nearest $0.1 \mathrm{~kg}$ with an electronic scale (BF 511, Omron) (Stewart et al. 2011). Each participant's BMI $\left(\mathrm{kg} /\right.$ height $\left.\left[\mathrm{m}^{2}\right]\right)$ was calculated from the individual height and body mass measurements. The WHO (2007) reference data were used as a standard to determine the Z-scores for height-for-age (HAZ), referred to as stunting, and weight-for-age (WAZ), known as wasting. Z-score values of less than -2 from the SD for HAZ were used to determine the prevalence of stunting. The Z-scores for wasting were determined by using BMI-for-age (De Onis et al. 2006). Three skinfolds were taken, namely the subscapular (two centimetres from the sub-scapular landmark, running obliquely and laterally downwards), the triceps (is a parallel skinfold, taken along the long axis of the upper arm at the triceps skinfold site) and medial calf (is a vertical measurement on the medial calf skinfold site) (Stewart et al. 2011). These skinfolds were measured by using a pair of Harpenden skinfold callipers and each measured twice to calculate an average measurement that was used for analysis (Stewart et al. 2011).

\section{Academic performance}

In Grade 1 (2010), during the June examinations, the Mastery of Basic Learning Areas Questionnaire was used to determine the academic performance of the different learning areas. A four-point scale was used, with 1 indicating not achieved, 2 partially achieved, 3 achieved and 4 outstanding achievement. Lastly, a cluster point was calculated from three variables: reading, writing and mathematics. In Grade 4 (2010), the June examination results were collected from all participating schools, and the same procedure was followed in 2016, when the learners were mainly in Grade 7. The learning areas according to the Department of Basic Education's Curriculum and
TABLE 1: Grading scales for Annual National Assessments.

\begin{tabular}{llc}
\hline Rating code & Description of competence & $\mathbf{\%}$ \\
\hline 7 & Outstanding achievement & $80-100$ \\
6 & Meritorious achievement & $70-79$ \\
5 & Substantial achievement & $60-69$ \\
4 & Adequate achievement & $50-59$ \\
3 & Moderate Achievement & $40-49$ \\
2 & Elementary achievement & $30-39$ \\
1 & Not achieved & $0-29$ \\
\hline
\end{tabular}

Source: Department of Basic Education, 2015, 'National Curriculum Statements (NCS) Grades $\mathrm{R}-12$ ', DBE, Republic of South Africa, viewed 24 May 2016, from https://www.education. gov.za/Curriculum/NationalCurriculumStatementsGradesR-12.aspx.\%20

Assessment Policy Statements (CAPS) are: mathematics, home language, second additional language, life orientation (LO), natural science (NS), social science and technology. Academic performances regarding Annual National Assessments (ANA) of September 2010 and 2013 were collected from all the learners who participated in this study. The ANA results of 2016 were also collected after the learners had completed the ANA examination in September 2016. The language and mathematics results of the learners were made available by the Department of Basic Education. All six learning areas as mentioned above were assessed by using the ANA grading scales (Table 1). The percentages were used regarding the ANA assessments.

\section{Data analysis and statistical procedures}

Statistica StatSoft (2017) was used to analyse the data. The Statistical Consultation Service of the university was consulted during the data analysis process. The data were analysed descriptively by using means (M), SD and minimum and maximum values. Two-way tables were used to determine the number of learners in each SES and their stunting or wasting status. Pearson Chi-square was used to indicate the significance of the relationships (stunting, wasting and academic performance), and the level of statistical significance was set at $p \leq 0.05$. The strength of the relationship was indicated by phi-coefficient, with $\mathrm{w} \approx 0.1$ indicating a small effect, $\mathrm{w} \approx 0.3$ a medium effect and $\mathrm{w} \geq 0.5$ a large effect. Analyses of variance (ANOVA) with Tukey's post hoc tests were used for each year to compare the classifications of the different SES, stunting and wasting over a period of 7 years, and the level of statistical significance was set at $p \leq 0.05$. Cohen's ' $\mathrm{d}$ ' was calculated to determine practical significant differences between standardised means. The following guideline values were used where an effect size of $d \approx 0.2$ indicates a small effect or practical non-significant difference, an effect size of $d \approx 0.5$ indicates a medium effect or practical visible difference and $d \approx 0.8$ a large effect or practical significant difference. These cut-off points were used as described by Cohen (1988).

\section{Ethical consideration}

Ethical approval for the execution of the project was obtained from the Ethics Committee of the North-West University, Potchefstroom Campus (No. NW-00070-09-A1, 2015/10/12). 
Permission was also obtained from the Department of Basic Education to gather data during school hours. Permission had also been obtained from all school principals of the schools that were identified to part take in this study. The parents or legal guardians of learners who participated in the study were requested to complete the informed consent forms whilst learners gave assent on the test-day. An effort was made to re-evaluate the same learners who had been evaluated in Grade 1 again during the two follow-up measurements. The data were collected by senior researchers and postgraduate students with a qualification in Human Movement Science, specialising in Kinderkinetics.

\section{Results}

The group consisted of 181 boys (63 Caucasian and 118 African and mixed race). Table 2 represents the descriptive statistics for 2010, 2013 and 2016, regarding age, stature, weight and BMI.

Two-way tables were used to determine the number of learners in each SES and their stunting or wasting status. Table 3 reports that wasting $(3.86 \%)$ overall had a higher percentage when compared with stunting (3.32\%) in 2010.

TABLE 2: Descriptive statistics for primary school boys over the period of 7 years (2010-2016).

\begin{tabular}{lrrrrr}
\hline Variable & $\boldsymbol{N}$ & Mean & Minimum & Maximum & SD \\
\hline 2010 & & & & & \\
Age & 181 & 6.9 & 6.0 & 7.8 & 0.4 \\
Stature & 181 & 120.8 & 102.1 & 141.7 & 6.5 \\
Weight & 181 & 23.1 & 16.4 & 45.9 & 5.0 \\
BMI & 181 & 15.7 & 12.6 & 26.8 & 2.2 \\
2013 & & & & & \\
Age & 181 & 9.9 & 9.0 & 10.7 & 0.4 \\
Stature & 181 & 136.1 & 117.0 & 161.0 & 6.9 \\
Weight & 181 & 32.6 & 19.6 & 65.6 & 8.8 \\
BMI & 181 & 17.5 & 12.9 & 30.8 & 3.4 \\
2016 & & & & & \\
Age & 181 & 12.9 & 11.9 & 13.7 & 0.4 \\
Stature & 181 & 152.6 & 131.9 & 178.8 & 9.2 \\
Weight & 181 & 45.3 & 23.1 & 100.8 & 13.5 \\
BMI & 181 & 19.3 & 14.0 & 36.5 & 4.2 \\
\hline
\end{tabular}

$N$, number of participants; SD, standard deviation; BMI, body mass index.
The same tendency was found in 2013; however, in 2016, stunting and wasting presented equal percentages (6.63\%). Further indicated by Table 3 is that more boys were stunted $(5.16 \%)$ in 2010 , when compared with wasting $(4.12 \%)$ amongst the low SES group. The opposite was found amongst the high SES group with wasting (3.57\%) being higher when compared with stunting (1.19\%). The same findings were obtained in 2013 (high and low SES) and 2016 (only low SES) with regard to the last finding of higher wasting percentages when compared with stunting. Furthermore, it is clear that boys from the low SES groups had higher percentages of stunting and wasting when compared with the percentages of boys from high SES groups (Table 3). Lastly, only one statistical significant relationship was reported over a period of 7 years in 2016 between wasting and high SES $(p=0.007)$.

Analyses of variances were used for each year to compare SES, stunting and wasting over a period of 7 years (see Tables 4 and 5). From Table 4, it is clear that SES affects academic performance. In 2010, numeracy ( $p=0.001)$, language $(p=0.004)$ and the average academic mark ( $p=$ $0.001)$ were statistically significant $(p \leq 0.05)$ when compared with SES. The same tendency was observed in 2013 between language, mathematics, average academic mark, language (department) and average academic mark (department). Furthermore, language, mathematics and average academic mark (for department as well) all reported a statistical significance in 2016. Effect sizes were further determined between SES (high and low), normal weight and stunting. In 2010, a medium effect was reported amongst the average academic mark and normal weight boys $(d=0.59)$. A large effect was also reported between language $(d=0.80)$, the average academic mark $(d=0.84)$ and stunting. Furthermore, a small effect was reported between numeracy $(d=0.23)$, language $(d=0.21)$ and the average academic mark $(d=0.23)$ and low SES. In 2013 , only mathematics $(d=0.84)$ reported a large effect amongst high SES. Lastly, in 2016, language reported a medium effect $(d=0.53)$ and mathematics (department) a large effect $(d=0.85)$ amongst boys with normal weight. Furthermore, a small effect was

TABLE 3: The relationship between socio-economic status, stunting and wasting over 7 years.

\begin{tabular}{|c|c|c|c|c|c|c|c|c|}
\hline \multirow[t]{2}{*}{ Variable } & \multicolumn{2}{|c|}{ Normal } & \multicolumn{2}{|c|}{ Stunting } & \multicolumn{2}{|c|}{ Wasting } & \multicolumn{2}{|c|}{ Overall } \\
\hline & $n$ & $\%$ & $n$ & $\%$ & $n$ & $\%$ & $n$ & $\%$ \\
\hline \multicolumn{9}{|l|}{2010} \\
\hline Low SES & 88 & 90.72 & 5 & 5.16 & 4 & 4.12 & 97 & 53.59 \\
\hline High SES & 80 & 95.24 & 1 & 1.19 & 3 & 3.57 & 84 & 46.41 \\
\hline Overall & 168 & 92.82 & 6 & 3.32 & 7 & 3.86 & 181 & 100.00 \\
\hline \multicolumn{9}{|l|}{2013} \\
\hline Low SES & 82 & 88.17 & 5 & 5.38 & 6 & 6.45 & 93 & 51.38 \\
\hline High SES & 83 & 94.32 & 2 & 2.27 & 3 & 3.41 & 88 & 46.62 \\
\hline Overall & 165 & 91.16 & 7 & 3.87 & 9 & 4.97 & 181 & 100.00 \\
\hline \multicolumn{9}{|l|}{2016} \\
\hline Low SES & 77 & 79.38 & 9 & 9.28 & 11 & 11.34 & 97 & 53.59 \\
\hline High SES & 80 & 95.24 & 3 & 3.57 & 1 & $1.19 *$ & 84 & 46.41 \\
\hline Overall & 157 & 86.74 & 12 & 6.63 & 12 & 6.63 & 181 & 100.00 \\
\hline
\end{tabular}

SES, socio-economic status.

$*, p \leq 0.05$. 
TABLE 4: Analyses of variances between normal weight, stunting and academic subjects per year.

\begin{tabular}{|c|c|c|c|c|c|c|c|c|c|c|c|c|c|}
\hline \multirow[t]{2}{*}{ Year } & \multirow[t]{2}{*}{ Subjects } & \multicolumn{2}{|c|}{ Normal Weight } & \multicolumn{2}{|c|}{ Stunting } & \multirow[t]{2}{*}{ MSE } & \multicolumn{3}{|c|}{$p$-values } & \multicolumn{2}{|c|}{ Effect size of SES } & \multicolumn{2}{|c|}{$\begin{array}{l}\text { Effect size (normal } \\
\text { weight and stunting) }\end{array}$} \\
\hline & & $\begin{array}{c}\text { Low } \\
\text { SES (M\%) }\end{array}$ & $\begin{array}{c}\text { High SES } \\
(\mathrm{M} \%)\end{array}$ & $\begin{array}{c}\text { Low } \\
\text { SES (M\%) }\end{array}$ & $\begin{array}{l}\text { High SES } \\
(\mathrm{M} \%)\end{array}$ & & Stunting & SES & $\begin{array}{l}\text { Stunting } \\
\text { and SES }\end{array}$ & $\begin{array}{l}\text { Normal } \\
\text { weight }\end{array}$ & Stunting & $\begin{array}{l}\text { Low } \\
\text { SES }\end{array}$ & $\begin{array}{l}\text { High } \\
\text { SES }\end{array}$ \\
\hline \multirow[t]{3}{*}{2010} & Numeracy & 70.97 & 84.72 & 66.67 & 81.25 & 348.5 & 0.34 & $\leq 0.001$ & 0.92 & $0.74 \ddagger$ & $0.78 \ddagger$ & $0.23 \dagger$ & 0.19 \\
\hline & Language & 66.33 & 75.86 & 62.08 & 78.13 & 397.8 & 0.82 & 0.004 & 0.45 & $0.48 \dagger$ & $0.80 \S$ & $0.21 \dagger$ & 0.11 \\
\hline & Average & 67.88 & 78.82 & 63.61 & 79.17 & 340.8 & 0.63 & $\leq 0.001$ & 0.57 & $0.59 \ddagger$ & $0.84 \S$ & $0.23 \dagger$ & 0.02 \\
\hline \multirow[t]{4}{*}{2013} & Language & 44.16 & 65.73 & 43.57 & 65.85 & 217.8 & 0.94 & $\leq 0.001$ & 0.91 & $1.46 \S$ & $1.51 \S$ & 0.04 & 0.01 \\
\hline & Average & 51.49 & 67.73 & 49.94 & 65.66 & 164.1 & 0.49 & $\leq 0.001$ & 0.92 & $1.27 \S$ & $1.23 \S$ & 0.12 & 0.16 \\
\hline & Language (ANA) & 43.61 & 69.39 & 36.74 & 62.00 & 264.0 & 0.04 & $\leq 0.001$ & 0.94 & $1.59 \S$ & $1.55 \S$ & $0.42 \dagger$ & $0.45 \dagger$ \\
\hline & Average (ANA) & 41.44 & 64.80 & 36.65 & 58.20 & 230.8 & 0.08 & $\leq 0.001$ & 0.78 & $1.54 \S$ & $1.42 \S$ & $0.32 \dagger$ & $0.43 \dagger$ \\
\hline \multirow[t]{5}{*}{2016} & Language & 55.72 & 62.33 & 50.82 & 59.50 & 155.5 & 0.08 & $\leq 0.001$ & 0.63 & $0.53 \ddagger$ & $0.70 \ddagger$ & $0.39 \dagger$ & $0.23 \dagger$ \\
\hline & Mathematics & 44.50 & 57.12 & 43.42 & 54.75 & 263.2 & 0.54 & $\leq 0.001$ & 0.82 & $0.78 \ddagger$ & $0.70 \ddagger$ & 0.07 & 0.15 \\
\hline & Average & 50.41 & 62.28 & 48.07 & 59.69 & 123.1 & 0.21 & $\leq 0.001$ & 0.95 & $1.07 \S$ & $1.05 \S$ & $0.21 \dagger$ & $0.23 \dagger$ \\
\hline & Language (Dep.) & 49.78 & 57.37 & 46.08 & 59.67 & 179.9 & 0.76 & $\leq 0.001$ & 0.20 & $0.57 \ddagger$ & $1.01 \S$ & $0.28 \dagger$ & 0.17 \\
\hline & Average (Dep.) & 41.91 & 56.90 & 41.33 & 58.99 & 118.7 & 0.69 & $\leq 0.001$ & 0.48 & $1.38 \S$ & $1.62 \S$ & 0.05 & 0.19 \\
\hline
\end{tabular}

ANA, Annual National Assessment; Dep., departmental marks; Average, average academic mark; SES, socio-economic status; MSE, mean square error.

$p \leq 0.05$.

Effect size: $d>0.2 \uparrow$ small effect, $d>0.5 \$$ medium effect, $d>0.8 \S$ large effect.

TABLE 5: Meaningful differences between normal weight, wasting and academic subjects per year.

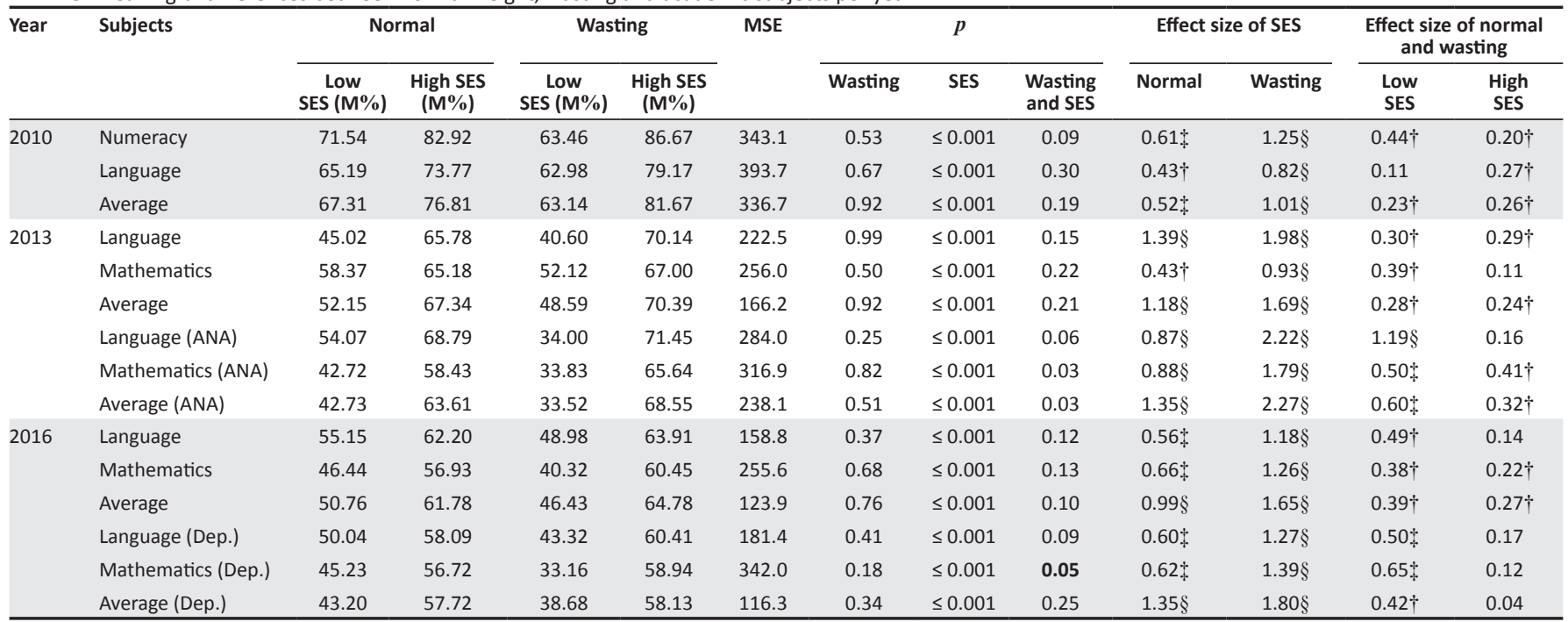

ANA, Annual National Assessment; Dep., departmental marks; Average, average academic mark; SES, socio-economic status, MSE, mean square error.

$p \leq 0.05$.

Effect size: $d>0.2 \uparrow$ small effect, $d>0.5 \$$ medium effect, $d>0.8 \S$ large effect.

found between language (department), the average academic mark and low SES $(d=0.21$ and $d=0.28$ respectively). The same was reported between the high SES for the average academic mark $(d=0.23)$. Lastly, it was seen that the participants who were diagnosed with stunting and living in the high SES reported higher percentages in all the academic skills over all 3 years than their peers with stunting in the low SES.

Table 5 reports the effect of wasting and SES on academic performance. Table 5 also reports that language, mathematics and average academic mark were statistically significant $(p \leq 0.05)$ when compared with SES in 2010. The ANA marks only represent the marks obtained by the ANA tests, whereas the department marks represent the term mark (including all tests and projects) per subject.
The same was reported in 2013 and 2016, with regard to language, mathematics, average academic mark, language (ANA), language (department), mathematics (department) and the average academic mark (department). Further, in 2013, statistical significance was found with regard to SES and wasting $(p=0.03)$ between mathematics (department) and the average academic mark (department). The same tendency was reported in 2016, where a statistical significance $(p=0.05)$ was reported with regard to the effect of SES and wasting on the mathematics marks (department). Effect sizes were determined for the relationships between wasting, normal weight and SES. A small effect was found between high SES, numeracy $(d=0.20)$, language $(d=0.27)$ and the average academic mark $(d=0.26)$ in 2010. The same effect was observed regarding low SES and the average academic mark $(d=0.23)$. Also reported in 2010 was a 
medium effect with regard to boys with normal weight $(d=0.52)$ and a large effect regarding wasting and SES $(d=0.82)$. In 2013, language $(d=0.29)$ and the average academic mark $(d=0.28)$ reported a small effect for the high SES. The same effect was observed for the relationship between the average academic mark and low SES $(d=0.24)$. A large effect was reported for language (ANA) and mathematics (ANA) amongst boys with normal weight ( $d=0.87$ and $d=0.88$ respectively). Also, a medium effect was found amongst mathematics (ANA) and low SES $(d=0.50)$. Language and language (department) both reported a medium effect amongst boys with normal weight and low SES respectively $(d=0.56$ and $d=0.50)$ in 2016. A small effect was observed amongst mathematics $(d=0.22)$ and the average academic mark $(d=0.27)$ with regard to high SES. In Table 5 it was seen that the participants who were diagnosed with wasting and living in the high SES reported higher percentages in all the academic skills over all 3 years than their peers with and without wasting living in high and low SES. In 2013 participants with wasting living in high SES also performed statistically $(p=0.03)$ better than their peers with and without wasting living in the different SES regarding their mathematics (ANA) and the average academic mark (ANA). However, in 2016 only statistical differences ( $p=0.05$ ) between the participants in the wasted group living in high SES and their peers with and without wasting living in high and low SES were reported for the mathematics (department) only.

\section{Discussion}

The aim of this study was to determine the effect of stunting and wasting on the academic performance of primary school boys over a period of 7 years in the North West Province of South Africa. This study found that the overall stunting and wasting percentage has increased from 2010 (3.32\% vs. 3.86\%) to 2016 (6.63\% vs. $6.63 \%)$. Furthermore, amongst the low SES, stunting and wasting percentages increased with each assessment. The same tendency was reported amongst the stunted boys in the high SES; however, a decrease in wasting was reported from 2010 (3.57\%) to 2016 (1.19\%). The study reported lower percentages when compared with studies conducted globally. This might be because of larger sample sizes in the other studies, which were also not longitudinal in nature. In a cross-sectional study conducted in South Nigeria, it was reported that $13 \%$ of their group was wasted and that the prevalence of wasting was higher in children aged 5-9 years (19\%) than in adolescents aged 10-18 years (8.3\%) (Ene-Obong et al. 2012). In South Africa, a study conducted by Shisana (2014) reported that the stunting prevalence amongst boys was the highest at age $0-3$ years $(26.9 \%)$ when compared with the 7-9-year-old boys (10\%). Symington et al. (2016) found that overall $17 \%$ of the children (3-9 years of age) in their study were stunted and that the lowest prevalence of stunting was found in the Gauteng Province (16.5\%) when compared with the Mpumalanga Province (18.2\%). Younger age groups were used as these are the ages during which stunting and wasting generally appears (Symington et al. 2016).
Poor academic performance has a positive correlation with stunting and wasting amongst boys. The current study found that, in 2010, the stunted (boys from high and low SES) and wasted (boys from low SES) boys had a significant association with language, mathematics and their average academic score. Additionally, in 2013 and 2016, language, mathematics and average academic scores (which included the departmental average academic scores as well) were mostly influenced by stunted (boys from high and low SES) and wasted (boys from low SES) boys. Furthermore, the only statistically significant relationships that were reported between wasting and SES over the period of 7 years were for the mathematics (ANA and department) in 2013 and 2016, and again with the academic average mark (ANA) in 2013, where the boys representing the wasting group in the high SES outperformed their peers with and without wasting in both the SES groups. A possible reason for these results could be because of the small number of participants $(n=3$ in 2013 and $n=1$ in 2016). However, these study results also indicated that children with stunting and wasting living in higher SES had higher academic percentages in all the subjects compared with their peers with stunting or wasting in lower SES. The findings are consistent with research that stated language and mathematics are the main subjects that are affected by stunting and wasting. This may be because of low school attendance, negative cognitive development and a lack of reading and/or writing (Kleinman et al. 2002). Jyoti, Frongillo and Jones (2005) have found that food insecurity will lead to a decline in academic performance regarding reading and mathematics. Certain studies (Miller et al. 2015; Prendergast \& Humphrey 2014) regarding stunting found that stunted and severely stunted children had lower cognitive abilities, enrolled late or not at all in school and had poor memory and lower academic performance. These children also had problems with learning, and it affected both the children's literacy skills and numeracy development. Rashmi et al. (2015) found strong relationships between children's nutritional status and academic performance. These researchers further reported that children who were wasted had lower grades in their first language and mathematics. South African studies (Matabane et al. 2012; Themane et al. 2003) found the same tendency where wasting had a positive association with poor academic performance, especially with regard to English and mathematics. According to Gallahue and Ozmun (2006), nutritional status is related to income status and provides evidence that children growing up in poor socio-economic environments are performing academically poorer. Children who are malnourished experience problems with regular school attendance, struggle to concentrate and solve problems during teaching sessions and lack motivation and energy to participate in the teaching process, according to Hughess and Bryan (2003). This could be a possible reason why the children living in higher SES with stunting or wasting outperformed the children with stunting or wasting living in lower SES. Additionally, an intervention study by Hollar et al. (2010) on elementary school children indicated that the intervention (food ingredients and whole food) group had higher mathematics 
and reading scores when compared with the control (wasted) group. Supporting these researchers, Jyoti et al. (2005) found that food insecurity impairs academic performance like reading and mathematics.

\section{Conclusion}

The study reported that stunting amongst primary school boys gradually increased from 2010 (3.32\%) to 2016 (6.63\%), and the same tendency was reported regarding the wasting amongst boys $(3.36 \%-6.63 \%)$. It is clear that the prevalence of stunting and wasting remained a major concern (including as a health risk) over a period of 7 years. Stunted and wasted children are at risk of various health issues, including low immune systems which will lead to more absent days from school and a lack of essential nutrients for development (physically and cognitively). Furthermore, the study reported that stunting and wasting amongst primary school boys lead to lower academic achievements when compared with children with normal weight and with SES being the most influential factor. From the literature, it is clear that stunting and wasting have a great effect on academic performance, especially amongst subjects such as mathematics and language. Valuable findings were reported; however, strengths and shortcomings were encountered. The study can be seen as a ground-breaking study in South Africa, because of its longitudinal (over the period of 7 years) nature, following the boys throughout the primary school. The study sample was randomly selected, which could lead to generalisation; however, the small sample size could have complicated this. The longitudinal effect of the study provided the researchers with valuable data with regard to stunting and wasting and academic performance. More studies are recommended in the other provinces of South Africa as this study concentrated only on the North West Province and more longitudinal studies in the South African setting should be conducted, to strengthen the findings. Lastly, a successful outcome for these results would be to influence the relevant parties to such an extent that nationwide intervention studies (e.g. physical activity intervention programmes) could be conducted to, for example, improve feeding schemes and lessen the effect of stunting and wasting; furthermore, it is recommended that special intervention is required for these disadvantaged children to remedy their academic skills.

\section{Acknowledgements}

The authors express their sincere gratitude to the Department of Education of the North West Province, the principals of the schools and the children for the permission granted to enable the researchers to complete this study.

\section{Competing interests}

The authors declare that they had no financial or personal relationships that might have inappropriately influenced in the writing of this article.

\section{Authors' contributions}

D.C. was the project leader and was part of the conceptualisation of this study. D.C., W.d.P. and D.v.S. were responsible for the collection of the data. Capturing the data was carried out by D.C. and D.v.S. All the authors read and approved of this article.

\section{Funding information}

The authors would also like to thank the National Research Foundation (NRF), Medical Research Council of South Africa (MRC) and the Sugar Association of South Africa (SASA) for the research grants that this project received.

\section{Data availability statement}

Data sharing is not applicable to this article.

\section{Disclaimer}

Any opinions, findings and conclusions or recommendations expressed in this material are those of the authors and therefore the NRF, MRC or SASA do not accept any liability in regard thereto.

\section{References}

Alaimo, K., Olson, C.M. \& Frongillo, E.A., 2001, 'Food insufficiency and American school-aged children's cognitive, academic, and psychosocial development', Pediatrics 108(1), 44-53.

Benefice, E., Monroy, S.L., Jime'nez, S. \& Lo'pez, R., 2006, 'Nutritional status of Amerindian children from the Beni river (lowland Bolivia) as related to environmental, maternal and dietary factors', Public Health Nutrition 9(3), 327-335. https://doi.org/10.1079/PHN2006852

Benton, D., 2010, 'The influence of dietary status on the cognitive performance of children', Molecular Nutrition and Food Research 54, 457-470. https://doi. org/10.1002/mnfr.200900158

Berkman, D.S., Lescano, A.G., Gilman, R.H., Lopez, S.L. \& Black, M.M., 2002, 'Effects of stunting, diarrhoeal disease, and parasitic infection during infancy on cognition in late childhood: A follow-up study', The Lancet 359 (9306), 564-571. https://doi. org/10.1016/S0140-6736(02)07744-9

Brown, J.L. \& Pollit, E., 1996, 'Malnutrition, poverty and intellectual development', Scientific America 274(2), 38-43. https://www.jstor.org/stable/24989396

Casale, D., Desmond, C. \& Richter, L., 2014, 'The association between stunting and psychosocial development among preschool children: A study using the South African Birth to twenty cohort data', Child: Care, Health and Development 40(6), 900-910. https://doi.org/10.1111/cch.12143

Chang, S.M., Walker, S.P., Grantham-McGregor, S. \& Powell, C.A., 2010, 'Early childhood stunting and later fine motor abilities', Developmental Medicine \& Child Neurology 52(9), 831-836. https://doi.org/10.1111/j.1469-8749.2010.03640.x

Cohen, J., 1988, Statistical power analysis for the behavioural sciences, 2nd edn., Lawrence Erlbaum, Hillsdale, NJ.

Cook, J. \& Jeng, K., 2009, 'Child food insecurity: The economic impact on our nation' Feeding America 7, 1-36. https://www.nokidhungry.org/sites/default/files/childeconomy-study.pdf.

Daniels, S.R., Eckel, R.H., Hayman, L.L., Kumanyika, S., Robinson, T.N. \& Stjeor, S., 2005, 'Overweight in children and adolescents', Circulation 111(15), 1999-2012. https://doi.org/10.1161/01.CIR.0000161369.71722.10

De Onis, M., Blössner, M. \& Borghi, E., 2011, 'Prevalence and trends of stunting among pre-school children, 1990-2020', Public Health Nutrition 15(1), 142-148. https:// doi.org/10.1017/S1368980011001315

De Onis, M., Onyango, A.W., Borghi, E., Garza, C. \& Yang, H., 2006, 'Comparison of the World Health Organization child growth standards and the national centre for health statistics/who international growth reference: Implications for child health programmes', Public Health Nutrition 9(7), 942-947. https://doi.org/10.1017/ PHN20062005

Department of Basic Education, 2015, 'National Curriculum Statements (NCS) Grades $\mathrm{R}-12$ ', DBE, Republic of South Africa, viewed 24 May 2016, from https://www. education.gov.za/Curriculum/NationalCurriculumStatementsGradesR-12. aspx.\%20.

Dewey, K.G. \& Begum, K., 2011, 'Long term consequences of stunting in early life', Matern Child Nutrition 7(3), 5-18. https://doi.org/10.1111/j.17408709.2011.00349.x 
Ene-Obong, H., Ibeanu, V., Onuoha, N. \& Ejekwu, A., 2012, 'Prevalence of overweight, obesity, and thinness among urban school-aged children and adolescents in southern Nigeria', Food and Nutrition Bulletin 33(4), 242-250. https://doi. southern Nigeria', Food and Nutrito
org/10.1177/156482651203300404

Gallahue, D.L. \& Ozmum, J.C., 2006, 'Understanding motor development. Infants, children, adolescents, adults', 6th edn., McGraw-Hill, New York.

Golam, H., Saimul, I., Enamul, K.H., Ashrufel, I., Asma, M., Kamruzzaman, M. et al., 2014, 'Prevalence of underweight and effect of nutritional status on academic performance of primary school children in Chapainawabganj District, Bangladesh', Malaysian Journal of Nutrition 20(1), 71-81.

Hall, K.H. \& Giese, S., 2009, 'Addressing quality through school fees and schoo funding', in S. Pendlebury, L. Lake \& C. Smith (eds.), South African child gauge, 2008/2009, pp. 35-40, Children's Institute, University of Cape Town, Cape Town.

Hollar, D., Messiah, S.E., Lopez-Mitnik, G., Hollar, T.L., Almon, M.R.D. \& Agatston, A.S. 2010 , 'Effect of a two-year obesity prevention intervention on percentile changes in body mass index and academic performance in low-income elementary school children', American Journal of Public Health 100(4), 646-653. https://doi. org/10.2105/AJPH.2009.165746

Hughess, D. \& Bryan, J., 2003, 'The assessment of cognitive performance in children: Considerations for detecting nutritional influences', Nutrition Reviews 61(12) 413-422. https://doi.org/10.1301/nr.2003.dec.413-422

Jyoti, D.F., Frongillo, E.A. \& Jones, S.J., 2005, 'Food insecurity affects school children's academic performance, weight gain, and social skills', The Journal of Nutrition 135(12), 2831-2839. https://doi.org/10.1093/jn/135.12.2831

Kleinman, R.E., Hallb, S., Greenc, H., Korzec-Ramirezd, D., Pattonb, K., Paganoe, M.E. et al., 2002, 'Diet, breakfast, and academic performance in children', National Institute of Health 46(01), 24-30. https://doi.org/10.1159/000066399

Kruger, G., Pienaar, A.E., Coetzee, D. \& Kruger, S.H., 2014, 'Prevalence of stunting, wasting and underweight in grade 1-learners: The NW-CHILD Study', Health SA/ Gesondheid 19(1), 1-7. https://doi.org/10.4102/hsag.v19i1.750

Kruger, H.S., Steyn, N.P., Swart, E.C., Maunder, E.M.W, Nel, J.H., Moeng, L. et al., 2012, 'Overweight among children decreased, but obesity prevalence remained high among women in South Africa, 1999-2005', Public Health Nutrition 15(4), 594599. https://doi.org/10.1017/S136898001100262X

Matabane, M.B., Liebenberg, M.W. \& Monyeki, K.D., 2012, 'Physical growth and academic intelligence of rural South African children: Ellisras longitudinal growth and health study', African Journal for Physical Health Education, Recreation and Dance 4(2), 912-920.

Matanda, D.J, Mittelmark M.B. \& Kigaru D.M.D., 2014, 'Child undernutrition in Kenya: Trend analyses from 1993 to 2008-09', BMC Pediatrics 14(5), 1-13. https://doi. org/10.1186/1471-2431-14-5

Mendez, M.A. \& Adair, L.S., 1999, 'Severity and timing of stunting in the first 2 years of life affect performance on cognitive tests in late childhood', The Journal of Nutrition 129(8), 1555-1562. https://doi.org/10.1093/jn/129.8.1555

Miller, A.C., Murray, M.B., Thomson, D.R. \& Arbour, M.C., 2015, 'How consistent are associations between stunting and child development? Evidence from a meta-analysis of associations between stunting and multidimensional child development in fifteen low- and middle-income countries', Public Health Nutrition 19(8), 1339-1347. https://doi.org/10.1017/S136898001500227X

Monyeki, K.D., Monyeki, M.A., Brits, S.J., Kemper, H.C.G. \& Makgae, P.J., 2008, 'Development and tracking of body mass index from preschool age into adolescence in rural South African children: Ellisras longitudinal growth an health study', Journal of Health, Population and Nutrition 26(4), 405-417. https:// doi.org/10.3329/jhpn.v26i4.1882

Motswagole, B.S., Kruger, H.S., Faber, M. \& Monyeki, K.D., 2012, 'Body composition in stunted, compared to non-stunted, black South African children, from two rura communities', South African Journal of Clinical Nutrition 25(2), 62-66. https://doi. org/10.1080/16070658.2012.11734407

Mushtaq, M.U., Gull, S., Khurshid, U., Shahid, U., Shad, M.A. \& Siddiqui, A.M., 2011, 'Prevalence and socio-demographic correlates of stunting and thinness among Pakistani primary school children', Biomed Central Public Health 11(790), 1-11. https://doi.org/10.1186/1471-2458-11-790

Nuñez, P.A., Fernández-Slezak, D., Farall, A., Szretter, M.E., Salomón, O.D. \& Valeggia, C.R., 2016, 'Impact of universal health coverage on child growth and nutrition in Argentina', American Journal of Public Health 104(4), 720-726. https://doi. org/10.2105/AJPH.2016.303056

Patil, R.C., Thakre, S.S., Khamgaonkar, M.B. \& Thakre, S., 2016, 'Prevalence of stunting and wasting among anganwadi school children of rural and urban area of central India: A cross-sectional study', International Journal of Medical Science and Public Health 6(2), 413-417. https://doi.org/10.5455/ ijmsph.2017.17082016634

Pearce, A., Scalzia, D., Lyncha, J. \& Smithers, L.G., 2016, 'Do thin, overweight and obese children have poorer development than their healthy-weight peers at the start of school? Findings from a South Australian data linkage study', Early Childhood Research Quarterly 35, 85-94. https://doi.org/10.1016/j ecresq.2015.10.007

Prendergast, A.J. \& Humphrey, J.H., 2014, 'The stunting syndrome in developing countries', Paediatrics and International Child Health 34(4), 250-265. https://doi. org/10.1179/2046905514Y.0000000158

Rashmi, M.R., Shweta, B.M., Fathima, F.N., Agrawal, T., Shah, M. \& Sequeira, R., 2015 'Prevalence of malnutrition and relationship with scholastic performance among primary and secondary school children in two select private schools in Bangalore Rural District', Indian Journal of Community Medicine 40(2), 97-102. https://doi. org/10.4103/0970-0218.153871
Saunders, J., Smith, T. \& Stroud, M., 2014, 'Malnutrition and undernutrition' Undernutrition and Clinical Nutrition Medicine 39(1), 45-50. https://doi. org/10.1016/j.mpmed.2010.10.007

Senbanjo, I.O., Oshikoya, K.A., Odusanya, O.O. \& Njokanma, O.F., 2011, 'Prevalence of and risk factors for stunting among school children and adolescents in Abeokuta, Southwest Nigeria', Journal of Health, Population and Nutrition 29(4), 364-370. https://doi.org/10.3329/jhpn.v29i4.8452

Sharaf, M.F. \& Rashad, A.S., 2016, 'Economic and socio-demographic determinants of child nutritional status in Egypt: A comprehensive analysis using quantile' Working paper, 1-21, viewed 12 June 2018, from https://sites.ualberta.ca/ econwps/2016/ wp2016-04.pdf.

Shisana, F., 2014, 'An analysis of diversification by location in the South African property market', MSc dissertation, University of Cape Town, Department of Economics.

Skosana, I., 2016, 'School feeding schemes help to grow young minds. Studies show that feeding programmes at schools not only reduce stunting, but also combat obesity and lead to increased enrolment in schools', Bhekisisa Centre of Health Journalism, viewed 12 June 2018, from http://bhekisisa.org/article/2016-03-07school-feeding-schemes-help-to-grow-young-minds.\%20.

Stats SA (Statistics South Africa), 2013a, Mid-year population estimates 2013, viewed 12 June 2018, from http://www.statssa.gov.za/publications/P0302/P03022013. pdf.

StatSoft, 2017, Statistica for windows: General conventions \& statistics, Statsoft, Tilsa, OK.

Steenkamp, L., Lategan, R. \& Raubenheimer, J., 2016, 'Moderate malnutrition in children aged five years and younger in South Africa: Are wasting or stunting being treated?', South African Journal of Clinical Nutrition 29(1), 27-31. https://doi.org/ 10.1080/16070658.2016.1215886

Stewart, A., Marfell-Jones, M., Olds, T. \& De Ridder, H., 2011, International standards for anthropometric assessment, The International Society for the Advancement of Kinanthropometry, Lower Hutt.

Sudfeld, C.R., McCoy, D.C., Fink, G., Muhihi, A., Bellinger, D.C., Masanja, H. et al., 2015, 'Malnutrition and its determinants are associated with suboptimal cognitive, communication, and motor development in Tanzanian children', The Journal of Nutrition 145(12), 2705-2714. https://doi.org/10.3945/jn.115.215996

Symington, E.A., Gericke, G.J., Nel, J.H. \& Labadarios, D., 2016, 'The relationship between stunting and overweight among children from South Africa: Secondary analysis of the national food consumption survey - Fortification baseline $I^{\prime}$, South African Medical Journal 106(1), 65-69. https://doi.org/10.7196/SAMJ.2016. v106i1.9839

Themane, M.J., Monyeki, K.D., Nthangeni, M.E., Kemper, H.C.G. \& Twisk, J.W.R., 2003, 'The relationship between health (malnutrition) and educational achievements (Maths and English) in the rural children of South Africa', International Journa of Educational Development 23(6), 637-643. https://doi.org/10.1016/S07380593(03)00063-4

Tomlinson, M., Hartley, M., Le Roux, I.M. \& Rotheram-Borus, M.J., 2016, 'The Philan mentor mothers intervention: Neighbourhood wide impact on child growth in Cape Town's peri-urban settlements', Vulnerable Children and Youth Studies 11(3) 211-220. https://doi.org/10.1080/17450128.2016.1214770

United Nations International Children's Emergency Fund, 2016, Levels and trends in child malnutrition, viewed 15 December 2016, from https://data.unicef.org/wpcontent/uploads/2016/09/UNICEF-Joint-Malnutrition-brochure.pdf.

Van Niekerk, L., Du Toit, D. \& Pienaar, A.E., 2015, 'The relationship between motor proficiency and academic performance of adolescent learners in Potchefstroom South Africa: PAHL study', African Journal for Physical, Health Education and Recreation and Dance 21(4:2), 1321-1336.

Victora, C.G., 1991, 'The association between wasting and stunting: An international perspective', The Journal of Nutrition 122(5), 1105-1110. https://doi.org/10.1093/ jn/122.5.1105

Victoria, C.G., Adair, L., Fall, C., Hallal, P.C., Martorell, R., Richter, L. et al., 2008, 'Maternal and child under nutrition: Consequences for adult health and human capital', Lancet 371(9), 340-357. https://doi.org/10.1016/S0140-6736(07)61692-4

Walsh, C.M., Dannhauser, A. \& Joubert, J., 2001, 'The impact of a nutrition education programme on the anthropometric nutritional status of low-income children in South Africa', Public Health Nutrition 5(1), 3-9. https://doi.org/10.1079/PHN2001204

Walton, E. \& Allen, S., 2011, 'Malnutrition in developing countries', Pediatrics and Child Nutrition 21(9), 418-424. https://doi.org/10.1016/j.paed.2011.04.004

Wingfield, R.J., McNamara, J.P.H., Janicke, D.M. \& Graziano, P.A., 2011, 'Is there a relationship between body mass index, fitness, and academic performance? Mixed results from students in a Southeastern United States elementary school', Current Issues in Education 14(2), 1-12.

Wisniewski, S.L., 2010, 'Child nutrition, health problems and school achievements in Sri Lanka', World Development 38(3), 315-332. https://doi.org/10.1016/j. worlddev.2009.09.009

World Health Organization, 2007, World health statistics 2007, viewed 15 June 2016 , from http://www.who.int/gho/publications/world_health_statistics/en/.

World Health Organization, 2014, World health statistics, viewed 08 May 2015, from http://www.who.int/gho/publications/world_health_statistics/en/.

World Health Organization, 2015, World health organization fact sheet, viewed 16 June 2015, from http://www.who.int/mediacentre/factsheets/fs311/en/.

World Health Organization, 2016, Levels and trends in child malnutrition, viewed 07 May 2017, from www.who.int/nutgrowthdb/estimates. 